\title{
EL ARBITRIO MUNICIPAL SOBRE INCREMENTO DEL VALOR DE LOS TERRENOS Y LA RED NACIONAL DE FERROCARRILES ESPAÑOLES
}

340.142

por

\section{Angel Sánchez Martín}

Secretario de primera categoría de Administración Local

SUMARIO: I. INTRODUCCION.-II. CONSIDERACIONES SOBRE LA ACTIVIDAD INDUSTRIAL Y MERCANTIL DEL ESTADO.-III. PERSONALIDAD JURIDICA DE LA RENFE.-IV. SUPUESTA EXENCION DE RENFE POR EL ARBITRIO DE PLUSVALIA.-V. TITULARIDAD .DOMINICAL DEL PATRIMONIO DE RENFE.-VI. CARACTER SUBJETIVO DE LA EXENCION.-VII. INTERPRETACION RESTRICTIVA DE LAS EXENCIONES FISCALES.-VIII. CRITERIO JURISPRUDENCIAL SOBRE LA SUJECION DE RENFE AL ARBITRIO.-IX. CONCLUSION. SUJECION AL ARBITRIO.$X$. NUEVA REGULACION DEL IMPUESTO DE PLUSVALIA.

\section{INTRODUCCION}

Por un Ayuntamiento se gira liquidación del arbitrio sobre incremento del valor de los terrenos para gravar la transmisión de los de una antigua estación de ferrocarril, transmisión hecha por la Renfe al Instituto Nacional de la Vivienda, liquidación que suponía una importante cantidad.

Notificada la liquidación, tanto al comprador como al vendedor, se interpusieron sendas reclamaciones económico-administrativas, fallando el Tribunal Económico-administrativo Provincial mandan- 
do anular la liquidación, en base a la exención del artículo 520, 1, a), de la Ley de Régimen local, al considerar, por aplicación del artículo 28 del Estatuto de la Renfe de 23 de julio de 1964, que los bienes de la Renfe son bienes del Estado, y que por lo tanto es de aplicación la exención establecida para éste por el citado precepto legal.

Interpuesto recurso contencioso-administrativo contra el fallo del Tribunal, la Sala de la Audiencia Territorial, por sentencia de 2 de noviembre de 1976, anula el fallo del Tribunal y declara ajustada a derecho la liquidación practicada. Apelada la sentencia por la Abogacía del Estado y por la representación de Renfe, el Tribunal Supremo, por otra de 21 de noviembre de 1977, desestima la apelación.

El presente estudio tiene por objeto exponer los argumentos favorables y contrarios a la exención de la Renfe por el arbitrio de plusvalía.

\section{CONSIDERACIONES SOBRE LA ACTIVIDAD INDUSTRIAL Y MERCANTIL DEL ESTADO}

Ha proliferado en los países occidentales a partir de la segunda guerra mundial la denominada actividad industrial y mercantil del Estado. El desarrollo de esta actividad suscitó la polémica de si debía considerarse a la misma como forma especial de la actividad de la Administración, de tal manera que junto a las clásicas formas de fomento, policía y servicio público hay que agregar la que Villar Palasí en su obra La actividad industrial del Estado en el Derecho administrativo denomina "gestión económica», o por el contrario, como sostiene Garrido Falla en su obra Las transformaciones del régimen administrativo, se trata simplemente de una actividad sometida al Derecho privado; sea cual fuere la postura que se adopte respecto a dicha polémica, lo cierto es que ha proliferado esta actividad mercantil o industrial del Estado a través de Entes descentralizados y normalmente con personalidad jurídica.

Siguiendo a García Oviedo y Martínez Useros, en su obra Derecho administrativo, se caracterizan las empresas públicas porque son empresas que se constituyen en todo o en parte con fondos públicos, y porque su actuación frente a terceros se produce de acuerdo con fórmulas propias del Derecho privado. 
A diferencia de la legislación del Régimen local que establece una regulación general de las empresas públicas al determinar las formas de gestión de servicios en el Reglamento de Servicios de las Corporaciones locales de 17 de junio de 1955, por lo que respecta a la Administración central no existe una regulación uniforme. Así, por ejemplo, está, entre otras, la Ley reguladora del Instituto $\mathrm{Na}$ cional de Industria, la Ley de Entidades estatales autónomas de 26 de diciembre de 1958 y las normas reguladoras de ciertas empresas como el caso de Renfe. La Ley de Entidades estatales autónomas regula las empresas nacionales como verdaderas empresas públicas, o sea en las que concurren los dos requisitos de constitución con fondos públicos y actuación frente a terceros con fórmulas de Derecho privado. Martínez Useros considera como empresas públicas propias a Renfe y a los Bancos oficiales, a diferencia de las impropias o mixtas, que no se constituyen en su totalidad con fondos estatales, sino que admiten participación de capital privado.

\section{PERSONALIDAD JURIDICA DE LA RENFE}

Las normas reguladoras de la Renfe son el Decreto-ley de 19 de julio de 1962, modificado por el de 23 de julio de 1964, y el Decreto de igual fecha de 1964 que aprobó el Estatuto de Renfe.

Conforme a tal normativa Renfe es una empresa pública propiedad en su totalidad del Estado; constituye un Ente descentralizado sobre el que el Estado ejerce sus funciones de tutela.

Renfe es una Entidad con personalidad de Derecho público, con personalidad jurídica independiente de la del Estado y con plena capacidad para el desarrollo de sus fines, sin perjuicio de las facultades que ejerza el Gobierno. Se destaca el hecho de que ostenta una personalidad propia e independiente de la del Estado (como se dice en el artículo $10^{\circ}$ del Decreto-ley y en el $10^{\circ}$ y $20^{\circ}$ del Estatuto). Tal personalidad se la reconoce, entre otras, en la sentencia del Tribunal Supremo de 25 de septiembre de 1971 (Aranzadi 3.515 ).

Además, actúa en régimen de empresa mercantil, carácter que se destaca en el artículo $10^{\circ}$ del Decreto-ley y en el $10^{\circ}$ y $4 .^{\circ}$ del Estatuto. Consecuencia de tal carácter mercantil es la recomendación o propósito de obtener una proporcionada rentabilidad de su capital (artículo $4 .^{\circ}$ del Estatuto) y la posibilidad de obtener benefi- 
cios (artículos $1 .^{\circ}$ y 11,8 , del Decreto-ley), concepto éste que precisamente se incluyó en los citados artículos en virtud de la modificación introducida por el Decreto-ley de 1964.

Incluso, como se dice en el artículo $3 .^{\circ}$ del Estatuto, «podrá promover o participar en otros negocios, sociedades o empresas».

Este carácter mercantil se destaca también al no sujetarse a las leyes de administración y contabilidad del Estado ni de Entidades estatales autónomas, y al no considerarse Administración pública a los efectos de las leyes de Procedimiento administrativo y jurisdiccionales (artículo 4..$^{\circ}$ del Estatuto), como reconoce la sentencia del Tribunal Supremo de 21 de noviembre de 1977 en su segundo considerando.

En conclusión, Renfe es una empresa mercantil con personalidad jurídica independiente, con obligación de obtener beneficios en su gestión, con la posibilidad de promover otras empresas o negocios distintos del transporte ferroviario; constituye en suma una manifestación de la actividad económica del Estado, concepto contrario, o cuando menos muy alejado, del de Administración pública, y que por tanto no debe gozar en principio del privilegio de la exención de impuestos.

\section{SUPUESTA EXENCION DE RENFE POR EL ARBITRIO DE PLUSVALIA}

El argumento central y único del fallo del Tribunal Económico, por el que anula la liquidación de plusvalía, consiste en determinar que el patrimonio de Renfe es patrimonio del Estado, y que, por tanto, a los bienes de Renfe les es de aplicación la exención establecida para el Estado en el artículo 520, 1, a), de la Ley de Régimen local de 24 de junio de 1955. Basa su argumentación en lo dispuesto en el artículo 28 del Estatuto de Renfe, que dice textualmente: "Los bienes integrados en Renfe conservarán los caracteres y condiciones que correspondan a los bienes del Estado con arreglo a las leyes, y, en especial, Renfe ejercerá, respecto de ellos, las facultades de recuperación posesoria que procedan según su naturaleza».

Añade, para reforzar la citada interpretación, que el Decreto de 7 de febrero de 1963 "atribuyó a la competencia de la Delegación del Gobierno en Renfe formar el inventario de los bienes del patrimonio estatal constitutivo de Renfe». 
Cita en apoyo de su tesis lo dispuesto en la sentencia del Tribunal Supremo de 6 de noviembre de 1971, mencionando literalmente que el patrimonio de la Renfe es en rigor patrimonio del Estado, «lo que viene a concordar y a sentar como principio general lo anteriormente argumentado, y dado el carácter de bienes del Estado de los mismos, no hay duda de que les es aplicable la exención del arbitrio de plusvalía a que se refiere el apartado a) del artículo 509».

\section{TITULARIDAD DOMINICAL DEL PATRIMONIO DE RENFE}

Por lo que respecta al patrimonio de la Renfe, hay alusiones al mismo en el artículo 2..$^{\circ}$ del Decreto-ley; el artículo 24 del Estatuto, que enumera los bienes que constituyen el patrimonio de Renfe; el 26, que alude también al patrimonio; el 25, que establece la obligación de llevar un inventario detallado de todos los bienes, muebles e inmuebles; el 27, que regula la facultad de enajenar los bienes muebles sin necesidad de previa desafectación, y que en cuanto a bienes inmuebles dispone la formalización de unos requisitos previos de autorización del Gobierno que en suma constituye una manifestación de las facultades de tutela sobre el Ente descentralizado que es Renfe, sin que haya base alguna para presuponer que las facultades del Gobierno sean demostrativas de la falta de titularidad dominical de Renfe sobre su patrimonio. El mismo artículo 28 en que se basa el fallo del Tribunal para el otorgamiento de la exención, constituye una manifestación palpable de que los bienes de Renfe son distintos de los bienes del Estado.

Se resalta que el Decreto de 7 de febrero de 1963, aludido en uno de los considerandos del fallo del Tribunal Económico, como demostrativo de que los bienes de Renfe son patrimonio estatal, no está vigente ni lo estaba en el momento del devengo del arbitrio, diciembre de 1969, por haber sido derogado por el artículo 15 del Decreto de 17 de diciembre de 1964, y como se confirma al no estar incluido en la relación de disposiciones vigentes anteriores al Estatuto, publicada por Decreto de 20 de julio de 1967.

Del estudio de los Estatutos antes mencionados y de las disposiciones autorizadas por el Estatuto, se desprende claramente que Renfe posee un patrimonio especial, un patrimonio propio distinto del peculiar del Estado. Tal es así, que tanto los bienes objeto de venta al Instituto Nacional de la Vivienda, por cuya venta se giró la 
liquidación de plusvalía, como otros bienes de Renfe, cuya venta también fue autorizada por el Decreto de 26 de diciembre de 1968, estaban inscritos en el Registro de la Propiedad a nombre de Renfe y no a nombre del Estado. Ello es una prueba palpable de la titularidad dominical de Renfe sobre los terrenos objeto de gravamen.

Discrepa esta parte respetuosamente del criterio mantenido en la sentencia del Tribunal Supremo de 6 de noviembre de 1971 (Aranzadi 4.565) cuando dice que al Estado corresponde la titularidad plena del patrimonio de Renfe de acuerdo con el artículo 28 del Estatuto. Precisamente del texto literal de este artículo se desprende con suficiente claridad que los bienes de Renfe no son bienes del Estado.

En las sentencias del Tribunal Supremo de 22 de febrero de 1971 (Aranzadi 537) y otra que menciona de 26 de febrero de 1968 (Aranzadi 1.172) se resolvió que «aun en el supuesto de estimarse que los bienes de la Red Nacional de los Ferrocarriles Españoles conservaran el carácter y condición de bienes del Estado», expresión que pone en tela de juicio la ostentación por los bienes de Renfe del carácter y condiciones de los bienes del Estado, y que a sensu contrario mantiene la postura de que no son bienes del Estado.

En definitiva, para esta parte la titularidad patrimonial de los bienes de Renfe no presenta duda alguna, corresponde a Renfe. Como persona jurídica que es tiene su propio patrimonio; que las facultades sobre el mismo tienen ciertas limitaciones, especialmente en materia de enajenación de bienes inmuebles (artículo 27) naturalmente, pero ello es debido a las facultades de tutela que ostenta el Estado sobre ella, pero el ejercicio de su tutela no es óbice para que Renfe sea titular dominical de su patrimonio, y como tal inscribe sus bienes inmuebles en el Registro de la Propiedad.

Tampoco es óbice a la citada conclusión el que Renfe sea una persona jurídica constituida en su totalidad con fondos del Estado.

Lo contrario sería como decir que los accionistas de una sociedad anónima son dueños de los bienes de la sociedad. La sociedad tiene su propio patrimonio, que administra, que lo destina a los fines estatutarios, que dispone de él, etc.; los bienes del patrimonio social son bienes de la sociedad. Y ello aunque simultáneamente los accionistas sean dueños de la sociedad. Igual ocurre en el caso de Renfe con el Estado. Renfe es dueña de su patrimonio, aunque el Estado sea dueño de Renfe.

En los organismos autónomos, el artículo 10 de la Ley de Régi- 
men jurídico de Entidades estatales autónomas de 26 de diciembre de 1958 dispone textualmente: "Los bienes que el Estado adscriba a los organismos autónomos para el cumplimiento de sus fines conservarán su calificación jurídica originaria. Los organismos que reciban dichos bienes no adquieren su propiedad, y los habrán de utilizar exclusivamente para el cumplimiento de sus fines, bien en forma directa, bien mediante la percepción de sus rentas o frutos". Del texto anterior se deduce que aquí sí se ha pronunciado claramente el legislador sobre la titularidad dominical del Estado en los bienes adscritos a los organismos autónomos; si el legislador se hubiera querido pronunciar en el artículo 28 del Estatuto de Renfe por la titularidad dominical del Estado, lo hubiera dicho expresamente. Pero no lo ha hecho.

La sentencia apelada, en su segundo considerando, no admite esta argumentación de la representación municipal, sino que declara que los bienes de Renfe son bienes estatales, criterio confirmado, dice la sentencia, por la del Tribunal Supremo de 6 de noviembre de 1971. Este considerando, junto con los demás de la sentencia apelada, es aceptado genéricamente por el Alto Tribunal y tenido por reproducido en la sentencia desestimatoria de la apelación.

No obstante lo dicho en el párrafo anterior, el criterio del Supremo sobre este punto, a nuestro juicio, difiere del mantenido por el Tribunal de Instancia, pues dice textualmente en uno de sus considerandos: «Que aquellos otros organismos autónomos que este Tribunal tiene declarado ser susceptibles de imposición por el arbitrio discutido, no obstante el hecho de que también en éstos los bienes que el Estado les adscriba para el cumplimiento de sus fines conserven su calificación jurídica originaria (artículo 10 de la Ley de 26 de diciembre de 1958), expresión de mayor alcance, sin duda, que la empleada para los integrados en la Renfe que según el artículo 28 del Estatuto, que es el precepto en que tenazmente permanece afincada ésta y la Administración apelante, conservará los caracteres y condiciones que correspondan a los bienes del Estado, pero sin estar integrados en su patrimonio como revela el texto del artículo 27 del tan repetido Estatuto, que prevé la incorporación al mismo a través del expediente que regula». Luego, confirmando la tesis municipal, está admitiendo la titularidad dominical de Renfe y no del Estado. 


\section{CARACTER SUBJETIVO DE LA EXENCION}

La exención establecida para el Estado en el artículo 520, 1, a), de la Ley de Régimen local es de tipo subjetivo, es decir, que se ha concedido el beneficio en atención a la Entidad titular de los bienes. En el mismo artículo y número hay otras exenciones de tipo subjetivo, como las de los apartados b) y j); también hay otras exenciones de tipo objetivo en atención al destino de los bienes. Esta distinción entre exenciones de tipo subjetivo y objetivo aparece claramente delimitada en los textos refundidos de ciertos impuestos estatales, así por ejemplo en los artículos 7 y 8 del Texto refundido de la Contribución urbana de 12 de mayo de 1966, y en los artículos 5 y 6 del Texto de la Contribución rústica de 23 de julio de 1966.

Al ser una exención de tipo subjetivo, no puede entenderse concedida a personas o Entidades distintas, por lo que no puede concederse a Renfe al ser una Entidad con personalidad jurídica independiente de la del Estado.

La jurisprudencia del Tribunal Supremo y de las Audiencias Territoriales confirman este criterio. Así, la sentencia de la Audiencia Territorial de Cáceres de 21 de abril de 1972, que recogiendo la doctrina del Tribunal Supremo considera que al Instituto Nacional de Colonización no le alcanza la exención del artículo 520, 1, a), por tener personalidad propia e independiente de la del Estado; se manifiesta en sus considerandos que en un impuesto análogo al de plusvalía, el de transmisiones patrimoniales y actos jurídicos documentados, cuyo Texto refundido es de 8 de abril de 1967, en su artículo 65 se establece la exención para el Estado, pero «sin que el béneficio alcance a Entidades u Organismos que, cualquiera que sea su relación de dependencia con el Estado, disfruten de personalidad propia e independencia de la de aquél, y no tengan reconocida por esta Ley exención especial", concluyendo que organismos como el Instituto Nacional de Colonización no tendrían exención del impuesto de transmisiones si la misma no estuviera recogida expresamente en el apartado b) del mismo precepto. Si esto sucede así en este impuesto, análogo al de plusvalía, si para disfrutar de exención tales organismos es precisa su cita expresa, cuando ésta no existe, como sucede en el artículo 520 de la Ley de Régimen local, «es que el legislador no quiso otorgar la exención». 
El argumento expuesto en el párrafo anterior es válido plenamente para el caso de Renfe, que tiene expresamente reconocida la exención del impuesto sobre transmisiones patrimoniales en un apartado distinto al del Estado, el $65,1,1^{\circ}, \mathrm{k}$ ).

En igual sentido se pronuncia la Audiencia de Cáceres en sentencias de 27 y 30 de mayo de 1972.

La sentencia del Tribunal Supremo de 30 de octubre de 1961 (Aranzadi 4.290) confirma la improcedencia de la exención del Instituto Nacional de Colonización por tener personalidad propia e independiente de la del Estado.

La sentencia del Tribunal Supremo de fecha 14 de diciembre de 1973 (Aranzadi 4.552) confirma la improcedencia de la exención para la Gerencia de Urbanización del Ministerio de la Vivienda por el hecho de tener personalidad jurídica independiente y añadiendo en su considerando tercero el argumento comparativo con el impuesto sobre transmisiones patrimoniales, que se ha expuesto con referencia a la sentencia de la Audiencia de Cáceres de 21 de abril de 1972.

La sentencia del Tribunal Supremo de 5 de noviembre de 1953 (Aranzadi 4.013) confirma igual criterio con respecto al Instituto Nacional de Colonización.

La exención reconocida en el artículo 520,1 , a), de la Ley de Régimen local a favor del Estado, es en resumen una exención subjetiva y que no se reconoce a organismos con personalidad propia e independiente de las del Estado, como es el caso de Renfe. Si no se reconoce la exención a los organismos autónomos que prestan servicios de naturaleza no económica normalmente, y que en sus relaciones con terceros están sometidos al Derecho público, al contrario que en el caso de Renfe, por lo que en este sentido están mucho más cercanos a la Administración estatal que Renfe, no puede reconocerse una exención a favor de esta Entidad.

Este argumento de la representación municipal ha sido confirmado plenamente tanto por el Tribunal Supremo como por el Tribunal de Instancia.

Se resalta el hecho de que los organismos autónomos carecen de exención, a pesar de que los bienes adscritos a los mismos son bienes propiedad del Estado como dispone el artículo 10 de su Ley reguladora, transcrito anteriormente. 


\section{INTERPRETACION RESTRICTIVA DE LAS EXENCIONES FISCALES}

La legislación y la jurisprudencia son claras en cuanto a la exigencia de que las exenciones hay que interpretarlas restrictivamente de un lado, y de otro, deben establecerse expresamente mediante disposición con rango de ley.

Así, el artículo 523 de la Ley de Régimen local, incluido en el epígrafe que trata de la plusvalía, que prohíbe a los Ayuntamientos reconocer otras exenciones que las taxativamente previstas en los artículos precedentes.

También el artículo 719 de la misma Ley, que establece que «la obligación de contribuir es siempre general en los límites de esta Ley, y en su consecuencia, ni aquellas Corporaciones ni el Gobierno podrán declarar otras exenciones que las concretamente previstas y autorizadas en ella, debiendo tenerse por expresamente derogada toda otra exención actualmente en vigor, aunque se funde en razones de equidad, analogía o equivalencia o en especial consideración de clase o fuero».

La Ley General Tributaria en su artículo 10, b), que determina la obligación de regular por ley el establecimiento de las exenciones tributarias.

Los artículos 14 y 15 de la misma Ley, que someten a restricciones el establecimiento y vigencia de las exenciones tributarias. Igualmente, el artículo 24,1 , de la misma Ley, que prohíbe la admisión de la analogía para extender más allá de los términos estrictos el ámbito de las exenciones.

Este mismo artículo 24, 1, fue mencionado en el considerando tercero de la sentencia del Tribunal Supremo de 14 de diciembre de 1973 (Ar. 4.552), de la que ya se ha hecho mención, lo que confirma el carácter restrictivo con que hay que interpretar las exenciones.

A mayor abundamiento, la sentencia del Tribunal Supremo de 5 de julio de 1968 (Ar. 3.621), en su considerando quinto, afirma literalmente: "Hoy más que nunca un principio fundamental -y precepto positivo de primer rango-, el de que no cabe admitir exenciones tributarias que no constan expresa e inequívocamente establecidas y por declaración legal en forma de ley». En tal sen- 
tencia se confirma una liquidación girada por impuesto industrial al no estar establecida expresamente la exención tributaria de Renfe.

En conclusión, no es aplicable a Renfe la exención establecida para el Estado en el artículo 520, 1, a), de la Ley local.

\section{CRITERIO JURISPRUDENCIAL SOBRE LA SUJECION DE RENFE AL ARBITRIO}

La sentencia del Tribunal Supremo de 14 de noviembre de 1958 (Aranzadi 3.554) por la que se confirma una liquidación de plusvalía practicada a Renfe por la venta de una finca adquirida por la Ley de 1941, de cuyos considerandos se desprende que la pretendida exención aquí rebatida sustentada por el fallo del Tribunal Econó-. mico ni siquiera fue alegada en los citados Autos, a pesar de que el artículo 518, 1, a), de la Ley de 16 de diciembre de 1950, Texto refundido vigente de la Ley local en el momento de la liquidación, regulaba la exención del Estado en los mismos términos que la actual, y a pesar de que Renfe estaba entonces menos descentralizada respecto al Estado que en la actualidad.

\section{CONCLUSION. SUJECION AL ARBITRIO}

Como sostenía la tesis municipal y ha sido confirmado por la Sala de lo Contencioso-administrativo de la Audiencia Territorial de Albacete y por el Tribunal Supremo en su sentencia mencionada de 21 de noviembre de 1977, la Renfe está sujeta al arbitrio sobre incremento del valor de los terrenos y no goza de la exención establecida para el Estado en el artículo 501, 1, a), de la Ley de Régimen local.

Esta sujeción se da tanto para el arbitrio que se devengue a consecuencia de transmisiones, como para el arbitrio en su modalidad de tasa de equivalencia.

La sujeción a la tasa de equivalencia de la Entidad Renfe se basa, de un lado, en la interpretación restrictiva de las exenciones fiscales, como se ha argumentado anteriormente, y en que la exención establecida por el artículo 516, 3, de la Ley de Régimen local para empresas concesionarias de servicios públicos tampoco le alcanza a Renfe por la sencilla razón de que no se trata de una empresa concesionaria, sino de una empresa pública del Estado. 
Podría pensarse que las anteriores conclusiones carecen de virtualidad después de la entrada en vigor del Decreto de 30 de diciembre de 1976 que regula el que denomina impuesto municipal sobre el incremento del valor de los terrenos, y en el que se establece una exención expresa a favor de Renfe. Pero lo cierto es que la regulación establecida en los artículos 510 a 524 de la Ley de Régimen local del 55 sigue vigente como derecho transitorio en virtud de lo establecido en la disposición transitoria quinta del Decreto de Haciendas locales para aquellos Municipios que todavía no hayan adaptado los Planes de Ordenación urbana a la Ley sobre el Régimen del Suelo y Ordenación urbana, y tales adaptaciones no se han realizado, es decir, no hay obligación de haberlas realizado, porque la disposición transitoria primera del Texto refundido de la Ley del Suelo de 9 de abril de 1976 concedió para ello un plazo de cuatro años ampliable a dos más. De ahí que la posibilidad de gravar a Renfe con el arbitrio tanto por transmisión de terrenos como en su modalidad de tasa de equivalencia pueda mantenerse de hecho y de derecho en bastantes Municipios.

\section{NUEVA REGULACION DEL IMPUESTO DE PLUSVALIA}

La Ley de Bases de Régimen local de 19 de noviembre de 1975 regula el impuesto municipal sobre incremento del valor de los terrenos en su Base 27.

Establece el impuesto en su número 1, en dos modalidades: a) la que se devenga por transmisión de terrenos; $b$ ) la que se devenga cuando los terrenos son propiedad de personas jurídicas, no habiendo transmisión. Esta segunda modalidad es similar a la actual tasa de equivalencia.

La materia de exenciones del impuesto está contenida en los números 6 y 7 de la citada Base. El número 6 recoge las exenciones subjetivas, entre las que se citan el Estado y sus organismos autónomos, además de otras entidades, instituciones y organismos, entre los que no se encuentra la Entidad de Renfe.

Está claro que Renfe no es un organismo autónomo, por así disponerlo expresamente el artículo $4 .^{\circ}$ del Estatuto de 23 de julio de 1964.

El número 7 dispone textualmente: «Se regularán en el texto articulado las exenciones y bonificaciones que por razones de inte- 
rés social o público deban ser reconocidas en la modalidad $b$ ). del número 1 de la presente Base.

En todo caso quedarán exentos del pago impuesto en la mencionada modalidad los terrenos destinados a centros de enseñanza reconocidos y autorizados por el Ministerio de Educación y Ciencia, sin perjuicio de que queden sometidos al presente impuesto cuando se produzca la transmisión de la propiedad".

De lo expuesto hasta ahora se desprende que en la Ley de Bases de 1975 no se estableció exención alguna a favor de Renfe.

El texto que articuló la Ley de Bases en materia de Haciendas locales es el Decreto 3.250, de 30 de diciembre de 1976, que regula el impuesto de plusvalía en sus artículos 87 a 98 . Pues bien, la materia de exenciones fiscales se recoge en el artículo 90 y las modalidades del impuesto en su artículo 87, 1.

Los números 1 y 2 del artículo 90 recogen las exenciones subjetivas del número 6 de la Base 27. Los números 3 y 4 desarrollan el 7 de la Base 27, diciéndose textualmente en el número 3: "Además de las exenciones que se mencionan en los dos números anteriores, gozarán de exención en la modalidad prevista en el artículo 87, 1, b), los incrementos de valor de: a) los terrenos destinados a centros de enseñanza reconocidos y autorizados por el Ministerio de Educación y Ciencia; $b$ ) los pertenecientes a Renfe».

Del examen de esta regulación se desprenden inicialmente dos consecuencias. Una, que el texto articulado recoge expresamente la exención de Renfe, a diferencia de lo establecido en la Ley de Bases. Y la otra, que la exención establecida para Renfe no es de tipo subjetivo, como la establecida, entre otrós, para el Estado y sus organismos autónomos.

Por lo que respecta a la inclusión de la exención de Renfe en el texto de 1976, cuando en el de 1975, Ley de Bases, no figuraba, y habiéndose dictado el 2 de noviembre de 1976 la sentencia de la Sala de lo Contencioso-administrativo de Albacete, declarando la no exención de Renfe, cabe sospechar que el legislador la tuviese en cuenta para favorecer a la empresa pública del Estado, regulando expresamente la exención. Ahora bien, como la enumeración de las exenciones de tipo subjetivo hecha en el número 6 de la Base 27 era limitada y no susceptible de ampliación, la inclusión de Renfe entre ellas hubiera significado excederse el legislador de lo que estaba facultado según la Ley de Bases. 
De ahí que la exención establecida para Renfe no sea de tipo subjetivo, a diferencia de lo establecido en el impuesto estatal similar, el de transmisiones patrimoniales, en el que sí se establece la exención de Renfe por razón de la Entidad, lo mismo que para el Estado y que para los organismos autónomos, tal como se dispone en el artículo $65,1,1^{\circ}$, del texto del impuesto.

¿Qué consecuencias se desprenden de que la exención de Renfe no tenga la condición de exención subjetiva?

Las consecuencias que a primera vista se observan son tres: a) que por aplicación de lo dispuesto en el artículo 90, 5, al producirse la transmisión de los terrenos pertenecientes a Renfe o cuando se graven con derechos reales de goce, tales actos jurídicos estarán sometidos al impuesto, y ello aunque se deduzcan de las cuotas las devengadas que hubieran sido objeto de exención; $b$ ) que en las adquisiciones de terrenos por parte de Renfe a título lucrativo se devengará el impuesto y estará obligada al pago en concepto de contribuyente, por aplicación de lo dispuesto en el artículo 91, 1, b); c) que en las adquisiciones de terrenos por parte de Renfe a título oneroso, esta Entidad tendrá la condición de sustituto del contribuyente, por aplicación de lo establecido en el artículo 91, 1, c), con las consecuencias que ello implica en cuanto a la exigibilidad de pago de la cuota. 